\title{
Highly Selective Adsorption on SiSe Monolayer and Effect of Strain Engineering: A DFT Study
}

\author{
Quan Zhou ${ }^{1}$, Lian Liu ${ }^{1}$, Qipeng Liu ${ }^{1}$, Zeping Wang ${ }^{1}$, Chenshan Gao ${ }^{1}$, Yufei Liu ${ }^{1,2}$ (1) \\ and Huaiyu $\mathrm{Ye}^{3,4, *}$ \\ 1 Key Laboratory of Optoelectronic Technology \& Systems, Education Ministry of China, College of \\ Optoelectronic Engineering, Chongqing University, Chongqing 400044, China \\ 2 Centre for Intelligent Sensing Technology, College of Optoelectronic Engineering, Chongqing University, \\ Chongqing 400044, China \\ 3 School of Microelectronics, Southern University of Science and Technology, Shenzhen 518055, China \\ 4 Shenzhen Institute of Wide-Bandgap Semiconductors, No.1088, Xueyuan Rd., Xili, Nanshan District, \\ Shenzhen 518055, Guangdong, China \\ * Correspondence: h.ye@tudelft.nl
}

Received: 16 December 2019; Accepted: 5 February 2020; Published: 12 February 2020

\begin{abstract}
The adsorption types of ten kinds of gas molecules $\left(\mathrm{O}_{2}, \mathrm{NH}_{3}, \mathrm{SO}_{2}, \mathrm{CH}_{4}, \mathrm{NO}, \mathrm{H}_{2} \mathrm{~S}, \mathrm{H}_{2}\right.$, $\mathrm{CO}, \mathrm{CO}_{2}$, and $\mathrm{NO}_{2}$ ) on the surface of SiSe monolayer are analyzed by the density-functional theory (DFT) calculation based on adsorption energy, charge density difference (CDD), electron localization function (ELF), and band structure. It shows high selective adsorption on SiSe monolayer that some gas molecules like $\mathrm{SO}_{2}, \mathrm{NO}$, and $\mathrm{NO}_{2}$ are chemically adsorbed, while the $\mathrm{NH}_{3}$ molecule is physically adsorbed, the rest of the molecules are weakly adsorbed. Moreover, stress is applied to the SiSe monolayer to improve the adsorption strength of $\mathrm{NH}_{3}$. It has a tendency of increment with the increase of compressive stress. The strongest physical adsorption energy $(-0.426 \mathrm{eV})$ is obtained when $2 \%$ compressive stress is added to the substrate in zigzag direction. The simple desorption is realized by decreasing the stress. Furthermore, based on the similar adsorption energy between $\mathrm{SO}_{2}$ and $\mathrm{NH}_{3}$ molecules, the co-adsorption of these two gases are studied. The results show that $\mathrm{SO}_{2}$ will promote the detection of $\mathrm{NH}_{3}$ in the case of $\mathrm{SO}_{2}-\mathrm{NH}_{3} / \mathrm{SiSe}$ configuration. Therefore, SiSe monolayer is a good candidate for $\mathrm{NH}_{3}$ sensing with strain engineering.
\end{abstract}

Keywords: SiSe monolayer; sensor; DFT; adsorption; stress

\section{Introduction}

As people care more about physical health and living environment, gas dectection [1,2], especially for the harmful gases has attracted much attention [3-7], such as the monitoring of indoor formaldehyde [8,9] gas content or the leakage of ammonia [10] in chemical plants. The detector can warn in advance when the gas leaks or is excessive. Thus, the gas sensor [11,12] requires sensitive materials which have ability to convert gas information into electrical signals, such as potential or resistance [13].

The principle of gas sensor includes chemical adsorption and physical adsorption. Chemisorption has strong interaction and a slow reaction rate caused by the chemical bond between adsorbent and adsorbate. On the contrary, physical adsorption is weak and faster caused by intermolecular Van der Waals attraction without chemical reaction and is easy to recover. Physisorption and chemisorption are not absolutely isolated from each other and can be changed from one to another. Adsorption properties of sensing materials can be adjusted through a variety of physical or chemical methods [14]. The weak interaction between adsorbate and adsorbent can be enhanced by heating [4], doping [15,16], and even 
possibly transformed into chemisorption, while strong adsorption can be weakened under the impact of charge injection [10] and electric field [17]. In addition, original chemical adsorption is converted to physical adsorption [18], which is in favor of gas sensing. However, the above-mentioned modification methods are characterized as instable and complex. Recently, Yu et al. have calculated that chemical adsorption of $\mathrm{NH}_{3}$ by $\mathrm{Ti}_{2} \mathrm{CO}_{2}$ substrate is improved by stress [19]. Ma et al. have explained that the moderate adsorption of $\mathrm{SO}_{2}$ was further enhanced by applying tensile stress [20]. Park et al. prepared the $\mathrm{MoS}_{2}$ bilayer on substrate by chemical vapor deposition (CVD) and utilized the load test machine of strain gauge presenting different strength [21]. Therefore, stress is a simple, effective, and suitable method for the adjustment of gas adsorption.

For high sensitivity detection, novel two-dimensional (2D) materials are considered to have great potential due to the quantum size effect [22] and exposed active sites. For example, graphene [23-25] or single-layer phosphorene [26-28] has attracted much attention because of high selectivity and sensitivity in adsorption behavior. In particular, the black phosphorus gas sensor has been confirmed by experiments to be a good detector for $\mathrm{NO}_{2}$ gas molecule [29]. The pleated structure of phosphorene is susceptible to strain $[30,31]$ and its electrical properties can be easily regulated through stress. However, inherent defects of phosphorene and instability in air hinder its further development. Recently, the SiSe monolayer [32,33], with similar structure of phosphorene has shown higher stability than phosphorene. Sa et al. proposed that the good stability of SiSe material is an ideal candidate of building block structure [34]. Yang et al. demonstrated that SiSe monolayers made from non-toxic and earth-abundant elements intrinsically have low thermal conductivities [35]. It is also reported that SiSe can be applied in a battery [36,37] due to large adsorption energies towards single $\mathrm{Na}$ and $\mathrm{Li}$ atoms, on account of the lower activation energy and rich active sites. These properties may also be expected to be utilized in gas sensor. Especially, an SiSe monolayer with abundant sources in the earth possesses a tunable electronic structure [38] and flexibility under stress, which is conducive to gas adsorption.

Herein, based on the density-functional theory (DFT), adsorption mechanisms and adsorption types of SiSe monolayer with different molecules $\left(\mathrm{O}_{2}, \mathrm{NH}_{3}, \mathrm{SO}_{2}, \mathrm{CH}_{4}, \mathrm{NO}, \mathrm{H}_{2} \mathrm{~S}, \mathrm{H}_{2}, \mathrm{CO}, \mathrm{CO}_{2}\right.$, and $\left.\mathrm{NO}_{2}\right)$ are studied. From the perspective of structure and electronic properties, the behavior of $\mathrm{NH}_{3}$ molecules on the SiSe substrate is physical adsorption with moderate adsorption energy, while $\mathrm{SO}_{2}, \mathrm{NO}$, and $\mathrm{NO}_{2}$ molecules on SiSe substrate show chemical adsorption with larger adsorption energy. Further, stress is used to adjust the adsorption performance. Results show that the adsorption of $\mathrm{NH}_{3}$ works best when $2 \%$ compressive stress is added to the substrate in zigzag direction, maintaining the maximum physical adsorption characteristics. It is also proved that the $\mathrm{NH}_{3}$ gas can be desorbed when the stress is removed. By contrast, the $\mathrm{SO}_{2}$ system exhibits stronger chemical adsorption under compressive stress. Then co-adsorption of $\mathrm{SO}_{2}$ and $\mathrm{NH}_{3}$ gas has also been studied due to the interference of each other. We find that the $\mathrm{SO}_{2}$ molecule promotes the adsorption of $\mathrm{NH}_{3}$ to some extent, which is advantageous as an $\mathrm{NH}_{3}$ gas sensor.

\section{Materials and Methods}

In this work, the DFT theory calculations is conducted by using the CASTEP module and $\mathrm{Dmol}^{3}$ package of Materials Studio, with generalized gradient approximations (GGA) [39] to Perdew-Burke-Ernzerhof (PBE) [40] functional for the exchange-correlation term [41]. In addition, the Grimme method is used as a dispersion correction to describe the interlayer Van der Waals interaction [42]. The systems are constructed with $3 \times 3 \times 1$ SiSe supercell as substrate and gas molecules are placed above the monolayer. Due to the difference between polar and non-polar molecules, non-spin polarization method is used in $\left(\mathrm{CO}_{2}, \mathrm{NH}_{3}, \mathrm{CO}, \mathrm{H}_{2} \mathrm{~S}, \mathrm{CH}_{4}, \mathrm{SO}_{2}\right.$, and $\left.\mathrm{H}_{2} \mathrm{O}\right) / \mathrm{SiSe}$ adsorption systems, and spin polarization calculation is used in $\left(\mathrm{NO}_{2}, \mathrm{O}_{2}\right.$, and $\left.\mathrm{NO}\right) /$ SiSe adsorption systems. The vacuum layer is set to $20 \AA$ in the $\left(\begin{array}{lll}0 & 0 & 1\end{array}\right)$ lattice plane to reduce periodic interaction between the layers in the vertical direction. In our simulation, the energy cutoff of the plane wave base is set as $500 \mathrm{eV}$. The brillouin zone integration is used for geometric optimization and electronic performance calculation on $16 \times 16 \times 1$ grid. All atomic coordinates and lattice constants gradually 
relax until a force converges within $0.01 \mathrm{eV} \AA^{-1}$ per atom and the tolerance of energy is less than $1.0 \mathrm{e}^{-5} \mathrm{eV}$ per atom. The adsorption energy is defined in the following equation [43]:

$$
E_{a}=E_{\text {SiSe }+ \text { gas }}-E_{\text {SiSe }}-E_{g a s}
$$

where $E_{S i S e+g a s}, E_{S i S e}$, and $E_{g a s}$ represent the total energy adsorbed by the gas on the SiSe substrate, the SiSe monolayer, and the gas molecules, respectively. Here we mainly focus on absolute value, the greater the absolute value of the adsorption energy, the stronger the interaction between the SiSe monolayer and the gas molecules.

The charge density difference (CDD) map is described to see the charge distribution of gas molecules with the substrate visually and qualitatively. The CDD is based on following definition with charge analysis [44]:

$$
\rho=\rho_{\text {gas }}+\text { SiSe }-\rho_{\text {SiSe }}-\rho_{\text {gas }}
$$

In this formula, $\rho_{\text {SiSe+gas }}, \rho_{\text {SiSe, }}$ and $\rho_{\text {gas }}$ represent the total charge density of the gas molecule/SiSe system, the original SiSe monolayer, and the isolated gas molecules. During the analysis, we need to be aware that each component should be in the same position in the adsorption structure.

Electron localization function (ELF) represents the electron location function and depicts the localized distribution characteristics of electrons. By definition, the value of ELF ranges from 0 to 1 , marked with blue and red in the map, respectively. When the value is close to 1 , this means the electrons of the atoms are highly localized and bonded together.

\section{Results and Discussion}

\subsection{Adsorption on SiSe Monolayer}

It begins with the geometry optimization of unit cell of SiSe. Then $3 \times 3 \times 1$ surface cell is constructed, including $9 \mathrm{Si}$ atoms and $9 \mathrm{Se}$ atoms in the surface cell. After full relaxation, the lattice constant of the armchair direction is $3.650 \AA$ (marked "a" in Figure 1), and the lattice constant of the zigzag direction is $4.647 \AA$ (marked " $b$ " in Figure 1) [38], which is similar to the structure of black phosphorus ( $4.57 \AA$ and $3.51 \AA$ respectively) [45]. The covalent bond length between Si-Se is tested

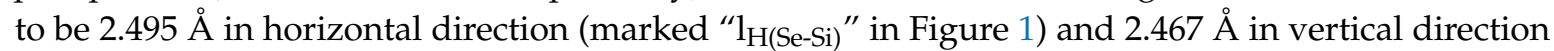
(marked " $\mathrm{V}_{\mathrm{V}(\mathrm{Se}-\mathrm{Si})}$ " in Figure 1), which is consistent with previous values [36]. Then, in analyzing the optimal adsorption position displayed in Figure 1, four different adsorption positions are considered, including the " $\mathrm{A}$ " position (right above Si-Se bond), the " $\mathrm{B}$ " position (on the top of the Si atom), "C" position (right above the center of the honeycomb area), and the " $\mathrm{D}$ " position (on the top of the Se atom). The different molecular orientations are also considered in Figure S1. All calculations and analyses are based on systems that the gas molecules at $3 \AA$ away from four sites [43]. After the four configurations converged, we select one configuration with the largest absolute value of the adsorption energy as the object of the next calculation, which is listed in Figure S2. Similarly, other adsorption systems are calculated in the same way. The optimized site of each adsorption system is shown in Table 1.

To discuss the difference in adsorption of different gases on SiSe monolayer, the adsorption energy and distance are calculated (seeTable 1). After full relaxation, $\mathrm{NO}$ and $\mathrm{NO}_{2}$ configurations manifest the biggest adsorption energy $(|-0.734| \mathrm{eV}$ and $|-0.735| \mathrm{eV}$, respectively) with the shortest adsorption distance (1.835 $\AA$ and $1.995 \AA$ ) among all the systems. In addition, the Se-Si bond enlarges to $2.608 \AA$ in the vertical direction and $2.409 \AA$ in the horizon direction, which are attributed to the strong interaction with the substrate. By contrast, compared with other gas configurations, $\mathrm{CO}, \mathrm{O}_{2}$, $\mathrm{CO}_{2}$, and $\mathrm{H}_{2} \mathrm{~S}$ molecules have repulsive interaction with the substrate, judged from their increased adsorption distance than the initial state. Other gas molecules like $\mathrm{H}_{2} \mathrm{O}$ are preliminarily considered as weak interaction with the substrate based on low adsorption energy. Specially, $\mathrm{NH}_{3}$ and $\mathrm{SO}_{2}$ configurations have moderate adsorption energy values $(|-0.414| \mathrm{eV}$ and $|-0.489| \mathrm{eV}$, respectively). The 
distance between adsorbates and adsorbents is reduced to $2.471 \AA$ and $2.733 \AA$, respectively. The Si-Se bond is slightly distorted, whose adsorption mechanisms are obscure and need further analysis.

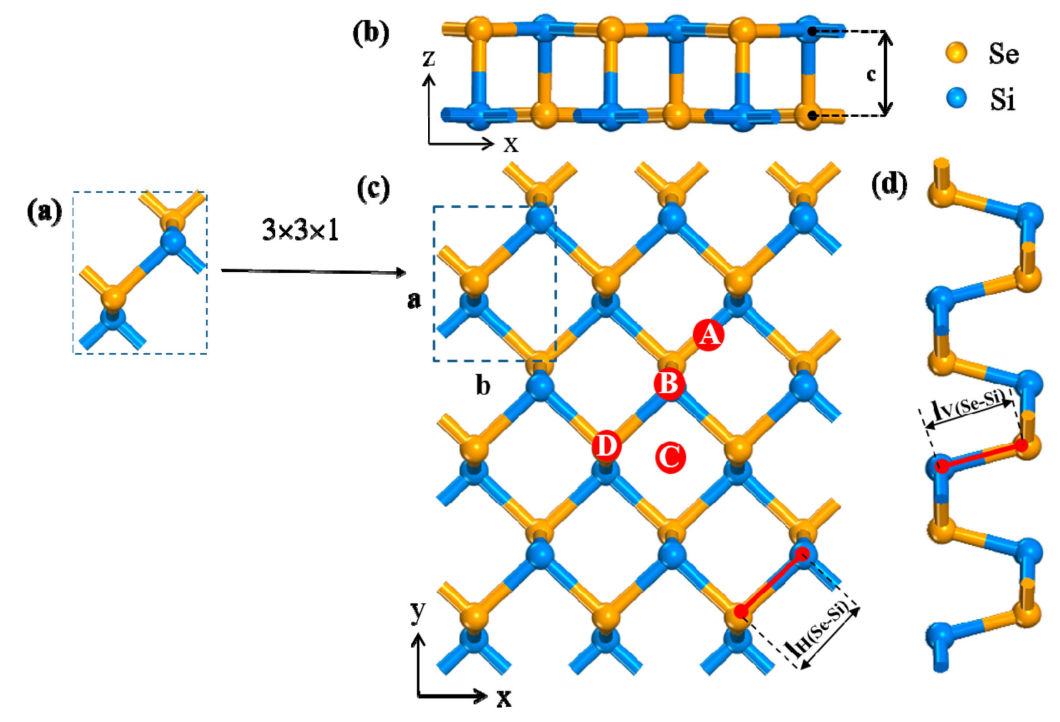

Figure 1. (a) Unit cell, (b) front, (c) top, and (d) side view of $\left(\begin{array}{lll}0 & 0 & 1\end{array}\right)$ lattice plane of substrate. The four sites " $\mathbf{A}$ ", "B", "C", and " $\mathbf{D}$ " are respectively labeled in the top view. " $\mathrm{x}$ ", " $y$ ", and " $\mathrm{z}$ " are the lattice directions. The marked "a" and "b" represent the lattice constant of unit cell.

Table 1. The optimal adsorption position, adsorption energy $\left(E_{a d}\right)$, closest distance $(d)$, charge transfer $(\Delta \mathrm{Q})$, and the length of Si-Se bond. The distance is defined as the nearest two atomic center distances between the gas molecules and the SiSe monolayer. $\Delta \mathrm{Q}$ is from Hirshfled/Mulliken population analysis, a negative value of $\Delta \mathrm{Q}$ represents that electrons are transferred from the SiSe monolayer to the gas molecule. The two values of SiSe bond represent the horizontal direction $\left(\mathrm{l}_{\mathrm{H}(\mathrm{Se}-\mathrm{Si})}\right) /$ vertical direction $\left(\mathrm{l}_{\mathrm{V}(\mathrm{Se}-\mathrm{Si})}\right)$.

\begin{tabular}{cccccc}
\hline Configuration & Site & $\mathbf{E}_{\mathbf{a d}}(\mathbf{e V})$ & $\mathbf{d}(\AA)$ & $\Delta \mathbf{Q}(\mathbf{e})$ & $\mathbf{S i - S e}(\AA)$ \\
\hline $\mathrm{CO}$ & $\mathrm{C}$ & -0.071 & 3.577 & $0.002 / 0.008$ & $2.497 / 2.462$ \\
$\mathrm{O}_{2}$ & $\mathrm{~B}$ & -0.098 & 3.067 & $-0.032 /-0.037$ & $2.492 / 2.467$ \\
$\mathrm{CO}_{2}$ & $\mathrm{D}$ & -0.132 & 3.424 & $-0.016 /-0.016$ & $2.495 / 2.469$ \\
$\mathrm{CH}_{4}$ & $\mathrm{~A}$ & -0.133 & 3.084 & $-0.066 / 0.022$ & $2.497 / 2.463$ \\
$\mathrm{H}_{2} \mathrm{~S}$ & $\mathrm{~A}$ & -0.203 & 3.405 & $0.068 / 0.080$ & $2.503 / 2.497$ \\
$\mathrm{H}_{2} \mathrm{O}$ & $\mathrm{C}$ & -0.237 & 2.805 & $-0.097 / 0.032$ & $2.487 / 2.463$ \\
$\mathrm{NH}_{3}$ & $\mathrm{~B}$ & -0.414 & 2.471 & $0.153 / 0.178$ & $2.503 / 2.658$ \\
$\mathrm{SO}$ & $\mathrm{A}$ & -0.489 & 2.686 & $-0.238 /-0.197$ & $2.448 / 2.441$ \\
$\mathrm{NO}$ & $\mathrm{B}$ & -0.734 & 1.835 & $-0.220 /-0.355$ & $2.417 / 2.528$ \\
$\mathrm{NO}_{2}$ & $\mathrm{~B}$ & -0.735 & 1.995 & $-0.285 /-0.386$ & $2.409 / 2.608$ \\
\hline
\end{tabular}

In order to clarify the interaction between molecules and SiSe monolayer, the CDD map and $\Delta \mathrm{Q}$ are calculated to see the charge distribution of gas molecules with the substrate qualitatively and quantitatively. We have listed some typical CDD maps that reflect the different degrees of interaction between the substrate and the gas molecules. The incremental tendency of adsorption strength is displayed from Figure 2a to Figure $2 \mathrm{f}$. In Figure 2a, the $\mathrm{CO}$ configuration has substantially no accumulation and consumption of charge at the interface with a little $\Delta Q$, and the same situation happens in the $\mathrm{CO}_{2}$ configuration (see Figure S3). In other systems, such as $\mathrm{O}_{2}, \mathrm{CH}_{4}$ etc., the substrate and the gas have a weaker charge rearrangement as shown in Figure $2 b$, which manifests the stronger interaction with the substrate than $\mathrm{CO}$ configuration. Yet the interaction is still much smaller. In Figure $2 c, d$, the range of charge redistribution of $\mathrm{NH}_{3}$ configuration and $\mathrm{SO}_{2}$ configuration are distinctly expanded. The charge is more severely depleted on the $\mathrm{NH}_{3}$ molecule, while the accumulation on the $\mathrm{SO}_{2}$ molecule is more serious, indicating that there is a strong interaction between the gas molecules and the substrate. Correspondingly, $\Delta \mathrm{Q}$ of these two systems is an order of magnitude larger than other six 
weak systems mentioned above. In the Figure $2 \mathrm{e}, \mathrm{f}$, the interaction between $\mathrm{NO}$ and $\mathrm{NO}_{2}$ structures still maintain the strongest position - the maximum range of charge rearrangement and a significant charge accumulation consumption. It shows, apparently, the loss of charge locates on the substrate, while the increase in charge is concentrated on the gas molecules, where charge is transferred from the gas molecule to the SiSe monolayer. In addition, the stronger interaction matches bigger charge transfer value (|-0.258| e) in $\mathrm{NO}_{2}$ configuration. It is worth noting that charge transfer of $\mathrm{SO}_{2} \mathrm{molecule}$ shows an abnormal change (|-0.238| e), increasing sharply compared to the $\mathrm{NH}_{3}$ molecule, even bigger than the NO molecule (|-0.220| e), which implies a different adsorption type from $\mathrm{NH}_{3}$ configuration.

\section{(a)}
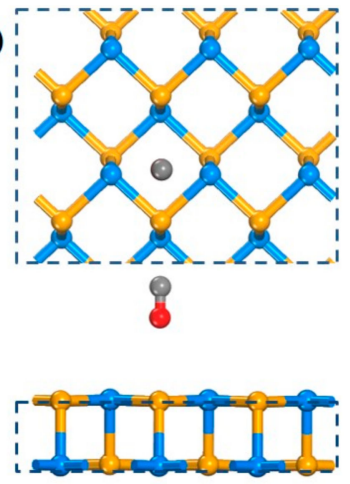

(d)

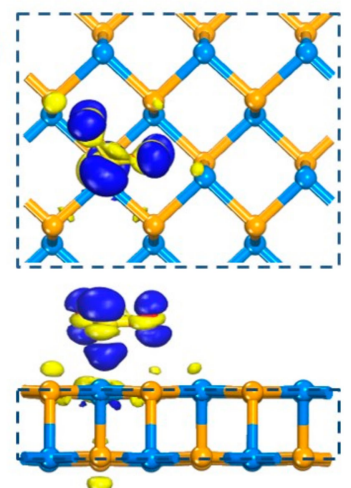

(b)

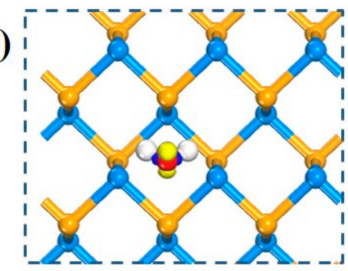

$\infty$

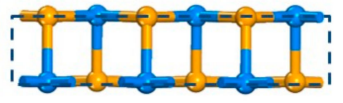

(e)

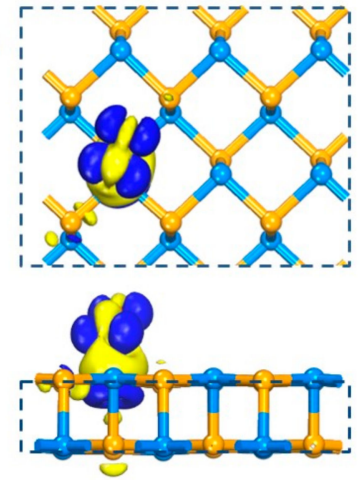

(c)
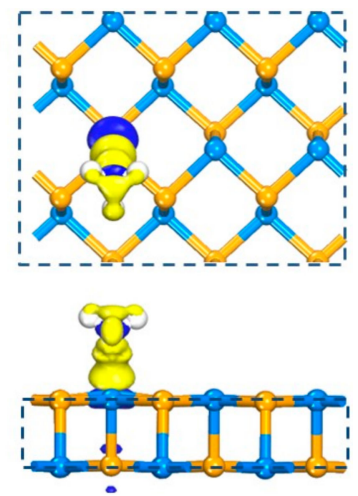

(f)

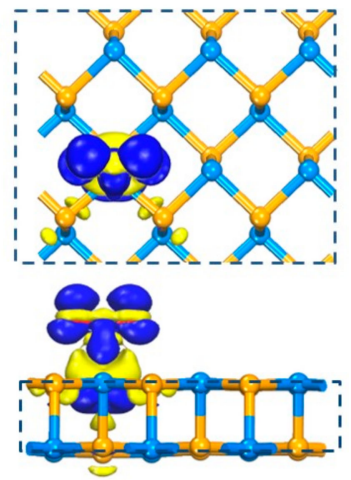

Figure 2. Front and top charge distribution view of charge density difference (CDD) maps, in turn are (a) $\mathrm{CO}$, (b) $\mathrm{H}_{2} \mathrm{O}$, (c) $\mathrm{NH}_{3}$, (d) $\mathrm{SO}_{2}$, (e) $\mathrm{NO}$, (f) $\mathrm{NO}_{2}$ configurations. The yellow part indicates charge loss, and the blue part indicates charge accumulation. The isosurface is set as $0.01 \mathrm{e} / \AA^{3}$.

Associated with ELF map in Figure 3a, it is clear to notice that the value of ELF between CO and SiSe substrate is close to 0 . There are hardly any electrons between $\mathrm{CO}$ molecule and SiSe substrate, which means no electron sharing and no covalent bonds exist in these two components. The same situation also occurs in systems like $\mathrm{CH}_{4}, \mathrm{H}_{2} \mathrm{O}, \mathrm{H}_{2} \mathrm{~S}$, and $\mathrm{O}_{2}$ (see Figure S4), which shows that these gas configurations are all physically adsorbed. In Figure $3 b$, the value of ELF in the border of $\mathrm{NH}_{3}$ and SiSe monolayer is nearly 0.5 , revealing that most electrons are still highly concentrated on the gas molecules and substrate, very little are delocalized in edge of junction. That is to say there exist very few electrons between $\mathrm{NH}_{3}$ and SiSe monolayer and it is not sufficient to form chemical bonds. On the contrary, it is distinct to see that electron densities of $\mathrm{S}$ and $\mathrm{Si}$ atoms are connected together and electrons are highly located between them in Figure 3c. It is highly possible to form S-Si covalent bond in the system. In the case of $\mathrm{NO}_{2}$ system in Figure 3d, the serious orbital overlaps between $\mathrm{N}$ atoms and $\mathrm{Si}$ atoms displays that they are bonded together, which reflects the chemical adsorption of $\mathrm{NO}$ and $\mathrm{NO}_{2}$ again.

To further confirm the adsorption type, the DOS and PDOS (total and partial densities of states) are calculated.Figure 4a shows plainly that DOS of pristine SiSe substrate is almost changeless near Fermi level before and after the $\mathrm{NH}_{3}$ is adsorbed on it. The big difference appears at around $-5 \mathrm{eV}$ in the valence band far away from Fermi level. In PDOS, it is obvious to find that there is no orbital overlap between $\mathrm{NH}_{3}$ molecule and SiSe monolayer near CBM (Conduction Band Minimum) or VBM 
(Valence Band Maximum). Hence physical adsorption occurs in $\mathrm{NH}_{3}$ and SiSe monolayer. In next Figure $4 b$, the DOS of SiSe is slightly offset after $\mathrm{SO}_{2}$ is adsorbed on SiSe near Fermi level from $-2 \mathrm{eV}$ to $-3 \mathrm{eV}$, and the peaks of orbitals between $\mathrm{S}$ atom and $\mathrm{Si}$ atom are overlapped at the energy of $-1 \mathrm{eV}$ in the valence band and $1 \mathrm{eV}$ in the conduction band. From Figure $4 \mathrm{c}, \mathrm{d}$, between $-8 \mathrm{eV}$ to $4 \mathrm{eV}$, the DOS of pristine SiSe monolayer is different from the adsorbed systems. The original electrical properties are destroyed when the $\mathrm{NO}_{2}$ is adsorbed on substrate. The chemical bond is formed with the more serious orbitals' hybridization, combined with the above analysis.

(a)

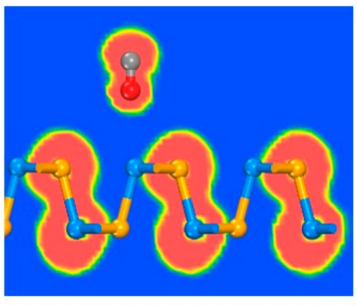

(c)

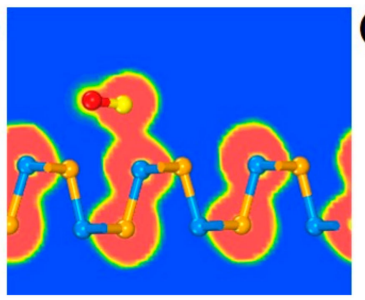

(b)

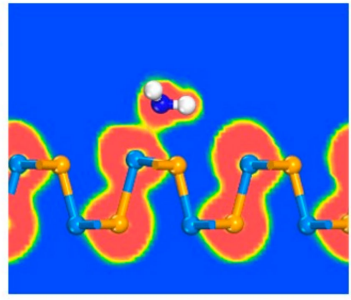

(d)

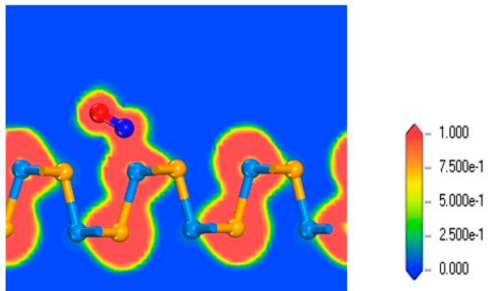

Figure 3. The distribution of electron localization maps of (a) $\mathrm{CO},(\mathbf{b}) \mathrm{NH}_{3}$, (c) $\mathrm{SO}_{2}$, and (d) $\mathrm{NO}_{2}$ configurations. The reference column for the electron localization function (ELF) value from 0 to 1 is located on the right side of the figure, representing blue and red, respectively. The slice of the ELF is parallel to the (100) crystal plane.
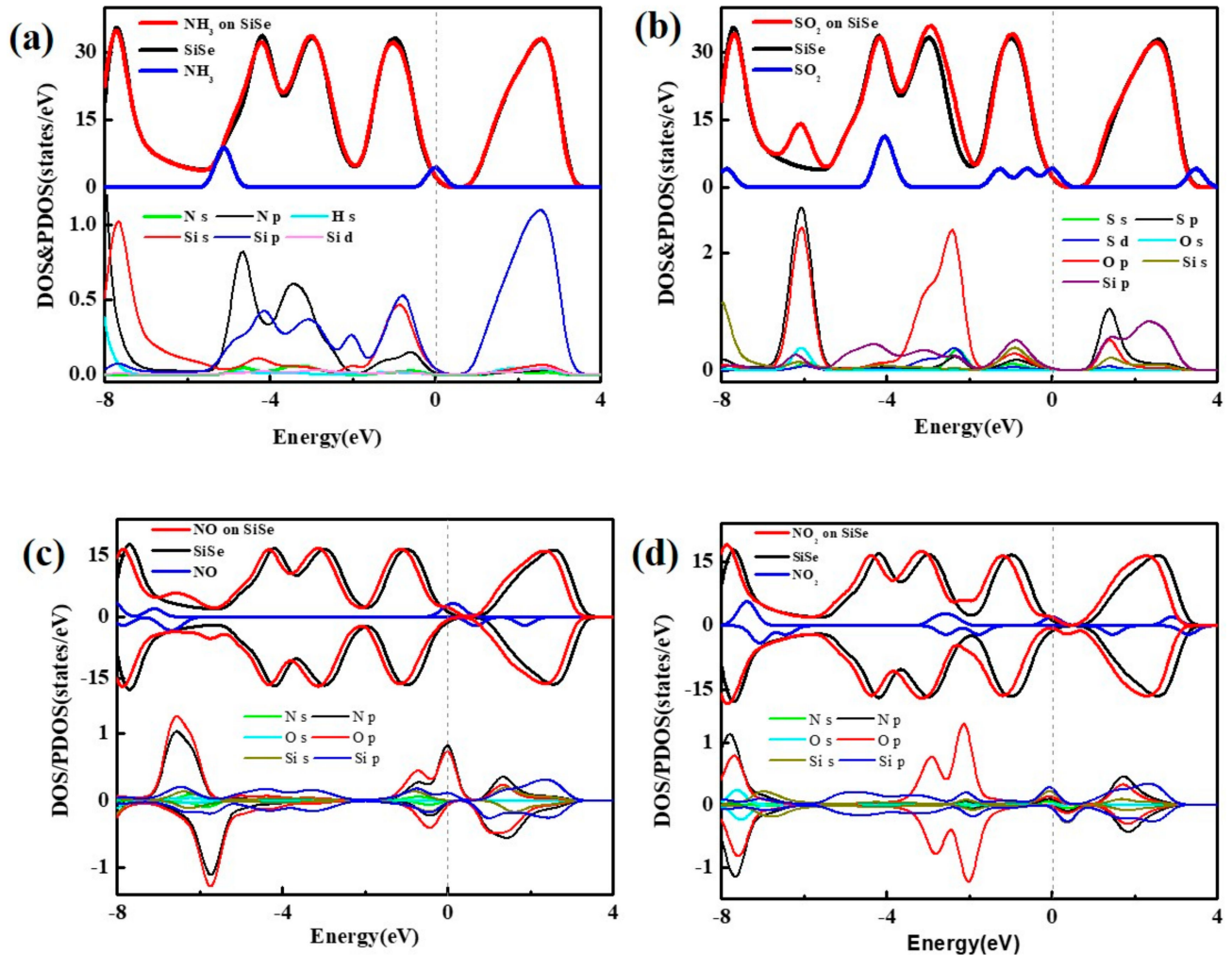

Figure 4. The DOS and PDOS maps of (a) $\mathrm{NH}_{3}$, (b) $\mathrm{SO}_{2}$, (c) $\mathrm{NO}$, and (d) $\mathrm{NO}_{2}$ molecules adsorbed on SiSe monolayer. 
In total, the high selectivity is displayed based on above analysis associated with the electronic analysis: the interaction between the $\mathrm{NH}_{3}$ gases and the SiSe monolayer is the strongest physical adsorption property with moderate adsorption energy $(-0.414 \mathrm{eV})$, which is larger than previous researches $[4,19,27]$, and makes it possible for SiSe monolayer to adsorb $\mathrm{NH}_{3}$ and easily desorb. $\mathrm{SO}_{2}, \mathrm{NO}$ or $\mathrm{NO}_{2}$ gases on the SiSe monolayer show the chemisorption property. The chemical reaction with substrate makes it difficult to reuse. The rest of the gases have very weak interaction with SiSe monolayer. They are all not suitable as a gas sensor based on the SiSe monolayer.

\subsection{Adsorption Mechanism of $\mathrm{NH}_{3}$ Under Stress}

Due to the special corrugated structure of SiSe, the adsorption property with SiSe monolayer under stress is discussed. Stress has been used to effectively regulate the mechanical, electrical, and magnetic properties of semiconductors over the past researches [46-49]. Previous theoretical and experimental studies indicate that the application of in-plane strain can adjust the band gap of SiSe monolayer [38], yet the performance of the SiSe monolayer adsorbing gas after the stress has not been studied. $\mathrm{NH}_{3}$ needs to be detected as a harmful gas, stress calculations are performed along the $\mathrm{X}$-axis (zigzag direction), Y-axis (armchair direction), and biaxial directions, respectively (shown in Figure 5). The stress is defined as: $\varepsilon=\left(a-a_{0}\right) / a_{0}$, where " $a_{0}$ " and " $a$ " are the lattice parameter of the original cell and strained-cell, respectively [19]. The gas is adsorbed on systems with the substrate stretched or compressed from $0 \%$ to $8 \%$ (also recorded $-8 \%$ to $8 \%$ ), the changes in various indexes after adsorption are observed.

(a)

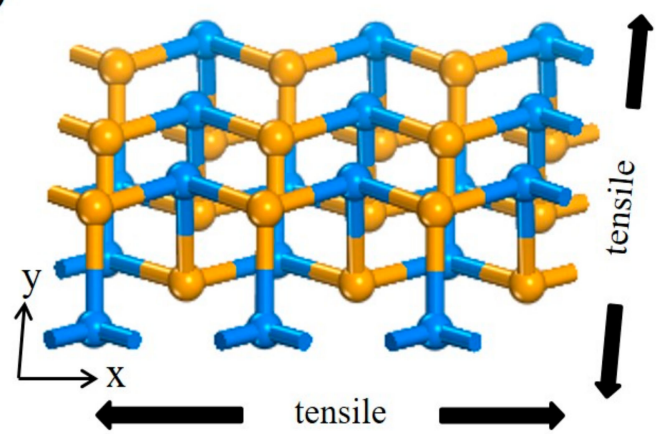

(b)

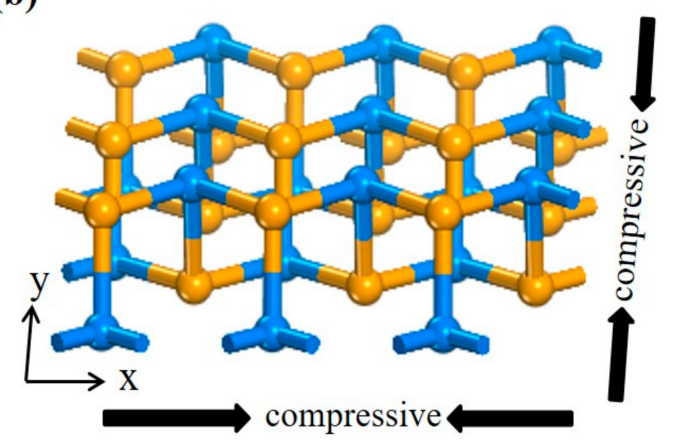

Figure 5. Schematic diagram of SiSe monolayer under in-plane (a) compressive (b) tensile stress from $\mathrm{X}$-axis, Y-axis, and biaxial direction.

\subsubsection{Compressive Direction}

First, under the uniaxial $\mathrm{X}$-axis compression, the adsorption energy is gradually increased. When the stress reaches $-8 \%$, the adsorption energy increases to a maximum value of $|-0.46| \mathrm{eV}$, which indirectly reflects the enhancement of the interaction between the $\mathrm{NH}_{3}$ molecule and the substrate. Further, this enhancement may result in the formation of covalent bonds between the $\mathrm{NH}_{3}$ molecule and the substrate. Therefore, the research on the ELF chart is performed. As present in Figure 6a, the electron local density of the $\mathrm{NH}_{3}$ molecules does not overlap with the SiSe substrate in ELF slice until the compressive stress reaches to $4 \%$, and it is seen that a covalent bond is likely to be formed, which is in the progressing direction that is unfavorable to the gas sensor. Thus, it shows the best adsorption efficiency when $-2 \%$ stress is added to the substrate. Similarly, the compressive strain trend in the $\mathrm{Y}$-axis and the biaxial are the same as the compressive strain trend in the $\mathrm{X}$-axis (as shown in Figure 6b). Only the degree of change is different: biaxial $>$ Y-axis $>\mathrm{X}$-axis. When the stress is from $-4 \%$ to $-8 \%$, the rate of change in adsorption energy is sharply increasing and the adsorption energy increases to $|-0.78| \mathrm{eV}$ at $-8 \%$, which is greater than the adsorption energy of $\mathrm{NO}_{2}$ system. At this time, observing the ELF diagram, it can be seen that the electron local density range of the $\mathrm{N}$ and $\mathrm{Si}$ atom are greatly hybridized (see inset of Figure $6 \mathrm{~b}$ ). A strong chemical bond is formed between the 
$\mathrm{N}$ and the Si atoms. That is to say, chemical adsorption is formed between the substrate and the gas, and the compressive stress enhances the adsorption of the gas.

(a)

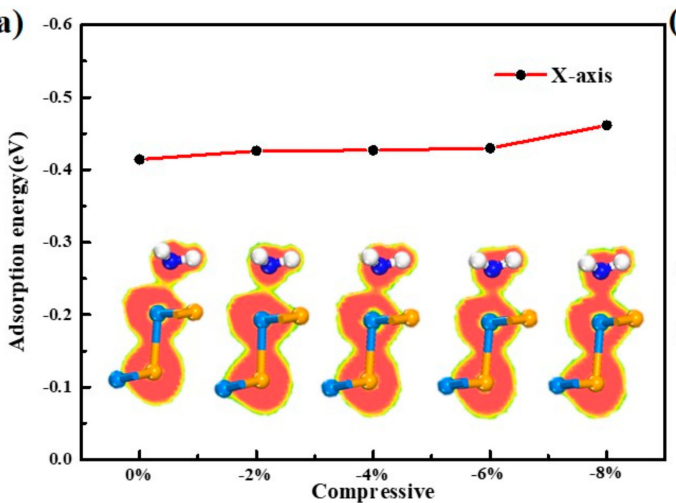

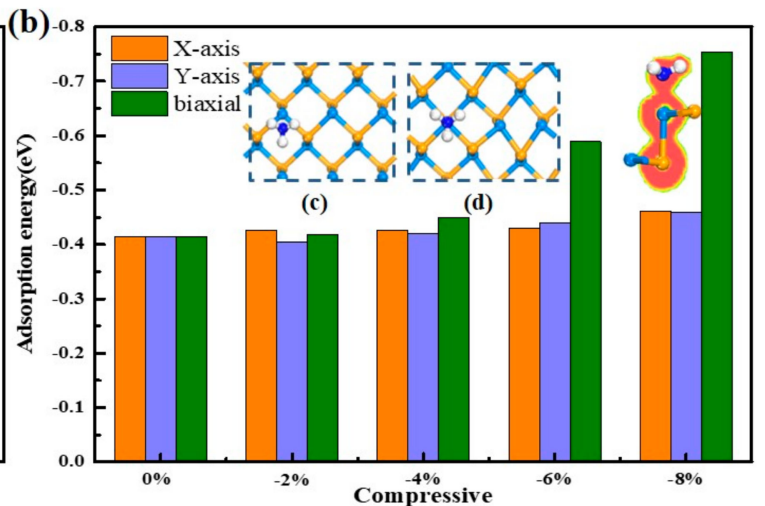

Figure 6. (a) The change curves of $\mathrm{E}_{a d}$ with compressive strain from $0 \%$ to $-8 \%$ in $\mathrm{NH}_{3} /$ strained-SiSe systems, ELF from left to right represents $0 \%,-2 \%,-4 \%,-6 \%$, and $-8 \%$ of stress. (b) The comparison of adsorption energy with $\mathrm{X}$-axis, $\mathrm{Y}$-axis, and biaxial under compressive strain from $0 \%$ to $-8 \%$ in $\mathrm{NH}_{3}$ /strained-SiSe systems, the data is shown in Table S1. The inset of (b) represents the ELF of $-8 \%$ biaxial of $\mathrm{NH}_{3} / \mathrm{SiSe}$ monolayer. The inset is morphology of $\mathrm{NH}_{3}$ system (c) without stress and (d) with $-8 \%$ stress in biaxial direction.

According to the reversibility of physical adsorption, we try to demonstrate the inverse process of the best adsorption position when $-2 \%$ pressure is applied to SiSe monolayer. The $-2 \%$ compression system that has completed the adsorption of $\mathrm{NH}_{3}$ is pulled back again to the original state of $0 \%$ stress-free state. After optimization, the adsorption energy, closest distance, $\Delta \mathrm{Q}$ and the bond of Si-Se are recorded in Table 2. Comparing the pulled back to the $0 \%$ system (label as $-2 \%$ to $0 \% \mathrm{NH}_{3} / \mathrm{SiSe}$ ) with $-2 \%$ compressive stress $-\mathrm{NH}_{3} / \mathrm{SiSe}$ (label as $-2 \% \mathrm{NH}_{3} / \mathrm{SiSe}$ ), it is discovered that adsorption energy is reduced to $|-0.413| \mathrm{eV}$, which is very close to $|-0.414| \mathrm{eV}$ at $0 \%$. Additionally, the length of the Si-Se bond and $\Delta \mathrm{Q}$ both recover to the situation of no stress, which shows an reverse process of gas desorption in gas sensor.

Table 2. The adsorption energy $\left(E_{\mathrm{ad}}\right)$, closest distance $(\mathrm{d})$, Mulliken charge transfer $(\Delta \mathrm{Q})$, and the Si-Se bond of horizontal and vertical direction.

\begin{tabular}{ccccc}
\hline Configuration & $\mathbf{E}_{\mathbf{a d}}(\mathbf{e V})$ & $\mathbf{d}(\mathbf{\AA})$ & $\Delta \mathbf{Q}(\mathbf{e})$ & $\mathbf{S i}-\operatorname{Se}(\AA)$ \\
\hline $0 \% \mathrm{NH}_{3} / \mathrm{SiSe}$ & -0.414 & 2.471 & 0.178 & $2.503 / 2.658$ \\
$-2 \% \mathrm{NH}_{3} / \mathrm{SiSe}$ & -0.426 & 2.443 & 0.184 & $2.482 / 2.669$ \\
$-2 \%$ to $0 \% \mathrm{NH}_{3} / \mathrm{SiSe}$ & -0.413 & 2.454 & 0.180 & $2.505 / 2.661$ \\
\hline
\end{tabular}

In the process of applying compressive stress to the substrate, the $\mathrm{NH}_{3}$ molecule is found to move close to the Si atom in Figure $6 c, d$. Moreover, the bond length of Si-Se, $\Delta Q$, and adsorption distance of the adsorption process of biaxial stress are carefully observed in Table 3 due to the obvious change among them. Without compression, after the adsorption is stabilized, the length of Si-Se bond are slightly distorted to $2.502 \AA$ in XY plane and $2.658 \AA$ in YZ plane respectively, the $\mathrm{NH}_{3}$ molecule will run toward the middle of the corrugate with the $\mathrm{Si}$ atom attracted to protrude from the substrate level, causing the substrate to be slightly deformed. As the biaxial compression increases, the $1_{\mathrm{H}(\mathrm{Se}-\mathrm{Si})}$ gradually decreases to $2.436 \AA$ and $2.444 \AA$. While the $\mathrm{l}_{\mathrm{V}(\mathrm{Se}-\mathrm{Si})}$ gradually increases to $2.701 \AA$, meanwhile the adsorption distance is gradually reduced to $2.226 \AA$, representing the strengthen interaction between the substrate and $\mathrm{NH}_{3}$ molecule. At this time, the $\mathrm{NH}_{3}$ molecules no longer run to the middle of the corrugate, but is more close to the $\mathrm{Si}$ atom without the silicon atoms prominent out of the horizon. This phenomenon can be explained by charge transfer. When there is no pressure, the $\Delta \mathrm{Q}$ of Si atom $(|0.605| \mathrm{e})$ and Se atom $(|-0.618| \mathrm{e})$ close to the $\mathrm{NH}_{3}$ molecule is very large. It can be 
seen that the $\mathrm{NH}_{3}$ molecule is not only attracted by the Si atom, but also restricted by the Se atom, so that the $\mathrm{NH}_{3}$ molecule will run to the middle, making Si-Se length in the vertical direction increases. As the pressure is applied, the $\Delta \mathrm{Q}$ of the Si atom $(|0.672| \mathrm{e})$ is gradually larger than that of the Se atom $(|-0.563| \mathrm{e})$, so that the attraction of the $\mathrm{Si}$ atom is dominant. Thus, the $\mathrm{NH}_{3}$ molecule is adsorbed towards the Si atom.

Table 3. Mulliken charge transfer $(\Delta \mathrm{Q})$ of $\mathrm{Si}$ atom closest to the $\mathrm{NH}_{3}$ molecule and connected Se atom, the nearest distance $(\mathrm{d})$ and the length of $\mathrm{Si}-\mathrm{Se}$ bond of $\mathrm{NH}_{3}$ gas molecule adsorbed on SiSe monolayer after biaxial stress from $0 \%$ to $-8 \%$.

\begin{tabular}{|c|c|c|c|c|c|c|}
\hline \multicolumn{2}{|c|}{ Parameter } & $0 \%$ & $-2 \%$ & $-4 \%$ & $-6 \%$ & $-8 \%$ \\
\hline \multicolumn{2}{|c|}{$\mathrm{d}(\AA)$} & 2.471 & 2.384 & 2.351 & 2.273 & 2.226 \\
\hline \multirow{2}{*}{$\Delta \mathrm{Q}(\mathrm{e})$} & $\mathrm{Si}$ & 0.605 & 0.600 & 0.607 & 0.644 & 0.672 \\
\hline & Se & -0.618 & -0.602 & -0.598 & -0.578 & -0.568 \\
\hline Si-Se & Horizontal & 2.502 & 2.494 & 2.472 & 2.460 & 2.444 \\
\hline Bond $(\AA)$ & Vertical & 2.658 & 2.662 & 2.672 & 2.679 & 2.701 \\
\hline
\end{tabular}

\subsubsection{Tensile Direction}

For $\mathrm{NH}_{3}$ configuration, the adsorption energy of the system decreases very little as the tensile force increases, which is contrary to the compression. The adsorption energy in the direction of X-axis slightly decreases to $|-0.396|$ e with the stretch increases, and the Y-axis direction decreases to the minimum value of $|-0.313|$ e with the stretch increases to $4 \%$, then conversely increases to $|-0.405|$ e at $8 \%$. It is noticed that the tensile stress in the Y-axis direction is more significant to the system, and the biaxial is the effect of the $\mathrm{X}$-axis and the $\mathrm{Y}$-axis. As the adsorption energy decreases, the effect of gas and substrate becomes weaker. Combined with ELF in Figure 7a, the range of $\mathrm{NH}_{3}$ molecule under biaxial stretching does not overlap with the SiSe monolayer, indicating no covalent bond is formed, thus the physical adsorption property remains.
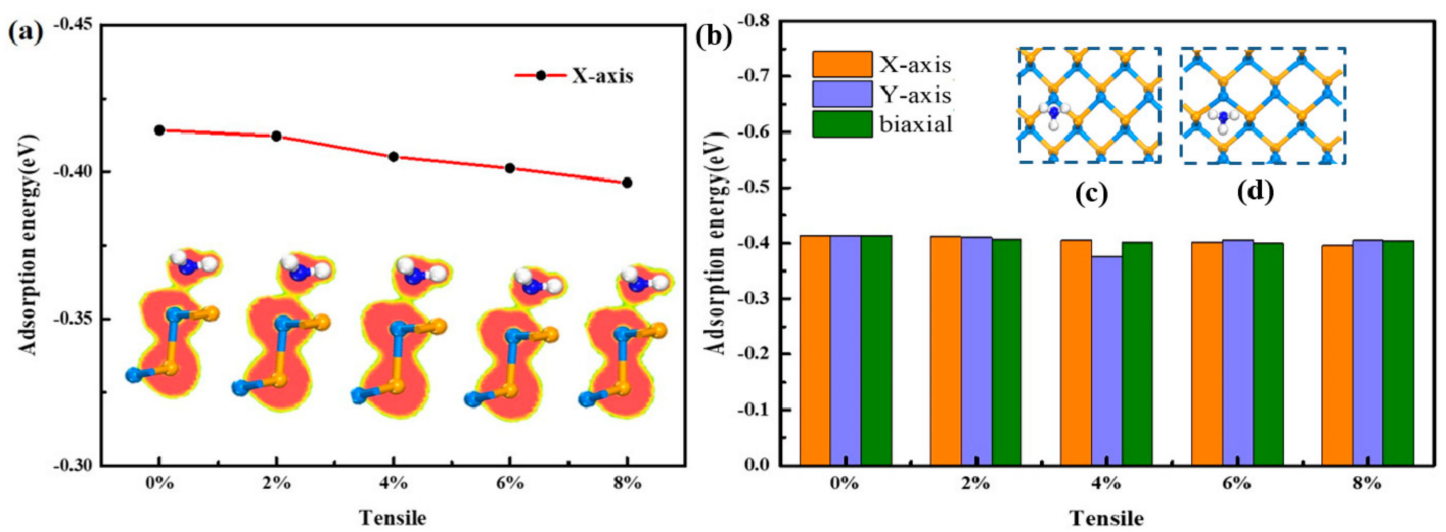

Figure 7. (a) The change curves of $\mathrm{E}_{a d}$ with tensile strain from $0 \%$ to $8 \%$ in $\mathrm{NH}_{3} /$ strained-SiSe systems, ELF from left to right represents $0 \%, 2 \%, 4 \%, 6 \%$, and $8 \%$ of stress. (b) The comparison of adsorption energy with the $\mathrm{X}$-axis, Y-axis, and biaxial under compressive strain from $0 \%$ to $8 \%$ in $\mathrm{NH}_{3} /$ strained-SiSe systems, the data is shown in Table S1. The inset is morphology of $\mathrm{NH}_{3}$ system (c) without stress and (d) with $8 \%$ stress in biaxial direction.

When the tensile stress is added to the substrate, the $\mathrm{NH}_{3}$ molecule moves to the honeycomb instead in Figure 7c,d. The mechanism is studied from the perspective of charge transfer and atomic orbital. First, it can be seen from the $\Delta \mathrm{Q}$ of the substrate that the Si atom closest to the $\mathrm{NH}_{3}$ molecule has a large $\Delta \mathrm{Q}$ and there is a strong interaction with the $\mathrm{NH}_{3}$ molecule mainly. However, the two Se atoms connected to the Si atom also have large $\Delta Q(|-0.618|$ e) that cannot be ignored. In total, the entire $\mathrm{NH}_{3}$ molecule is simultaneously constrained by these relatively active Se atoms. As the stretching enlarges, the $\Delta \mathrm{Q}$ of Se atom increases to $|-0.627|$ e at $8 \%$ with the enhancement of constraint 
action, so that the entire $\mathrm{NH}_{3}$ molecule is attracted to the middle of the honeycomb. Hence, the Si atom follows the movement of the $\mathrm{NH}_{3}$ molecule and the Se-Si bond in the vertical direction becomes longer inTable 4.

Table 4. Mulliken charge transfer $(\Delta \mathrm{Q})$ of $\mathrm{Si}$ atom closest to $\mathrm{NH}_{3}$ molecule and connected Se atom, the nearest distance (d) and the length of Si-Se bond of $\mathrm{NH}_{3}$ gas molecule adsorbed on SiSe monolayer after biaxial stress from $0 \%$ to $8 \%$.

\begin{tabular}{|c|c|c|c|c|c|c|}
\hline \multicolumn{2}{|c|}{ Parameter } & $0 \%$ & $-2 \%$ & $-4 \%$ & $-6 \%$ & $-8 \%$ \\
\hline \multicolumn{2}{|c|}{$\mathrm{d}(\AA)$} & 2.471 & 2.503 & 2.518 & 2.479 & 2.465 \\
\hline \multirow{2}{*}{$\Delta \mathrm{Q}(\mathrm{e})$} & $\mathrm{Si}$ & 0.605 & 0.606 & 0.607 & 0.609 & 0.610 \\
\hline & Se & -0.618 & -0.619 & -0.626 & -0.624 & -0.627 \\
\hline Si-Se & Horizontal & 2.502 & 2.527 & 2.551 & 2.572 & 2.596 \\
\hline Bond $(\AA)$ & Vertical & 2.658 & 2.649 & 2.649 & 2.663 & 2.679 \\
\hline
\end{tabular}

In the following, the band structure and atomic orbital are discussed to have an in-depth exploration. In the absence of stress displayed in Figure 8a, the system has an indirect band gap of 1.108 eV. Presented in PDOS, the valence band is mainly contributed by the $4 p$ orbital of the Se atom, and the conduction band is mainly contributed by the $3 p$ orbital of the Si atom, which is in accordance with the HUMO (Highest Occupied Molecular Orbital) and LUMO (Lowest Unoccupied Molecular Orbital) in Figure 8c,d. As the tensile force increases, the bandgap of the system increases to $1.295 \mathrm{eV}$. This may be the reason that the tensile force increases the lattice constant of the substrate and the distance between the atoms becomes larger, thus the energy level of each atom becomes more discrete. The contribution of the P orbital of Se to the conduction band increases, and the effect of Se increases under the tensile force, which is consistent with the previous analysis. At the same time, the contribution of the $\mathrm{Si}$ atom to the valence band has also increased, but there is not much increase in Se, and finally the comprehensive influence of the substrate on the adsorption of $\mathrm{NH}_{3}$ is weakened.
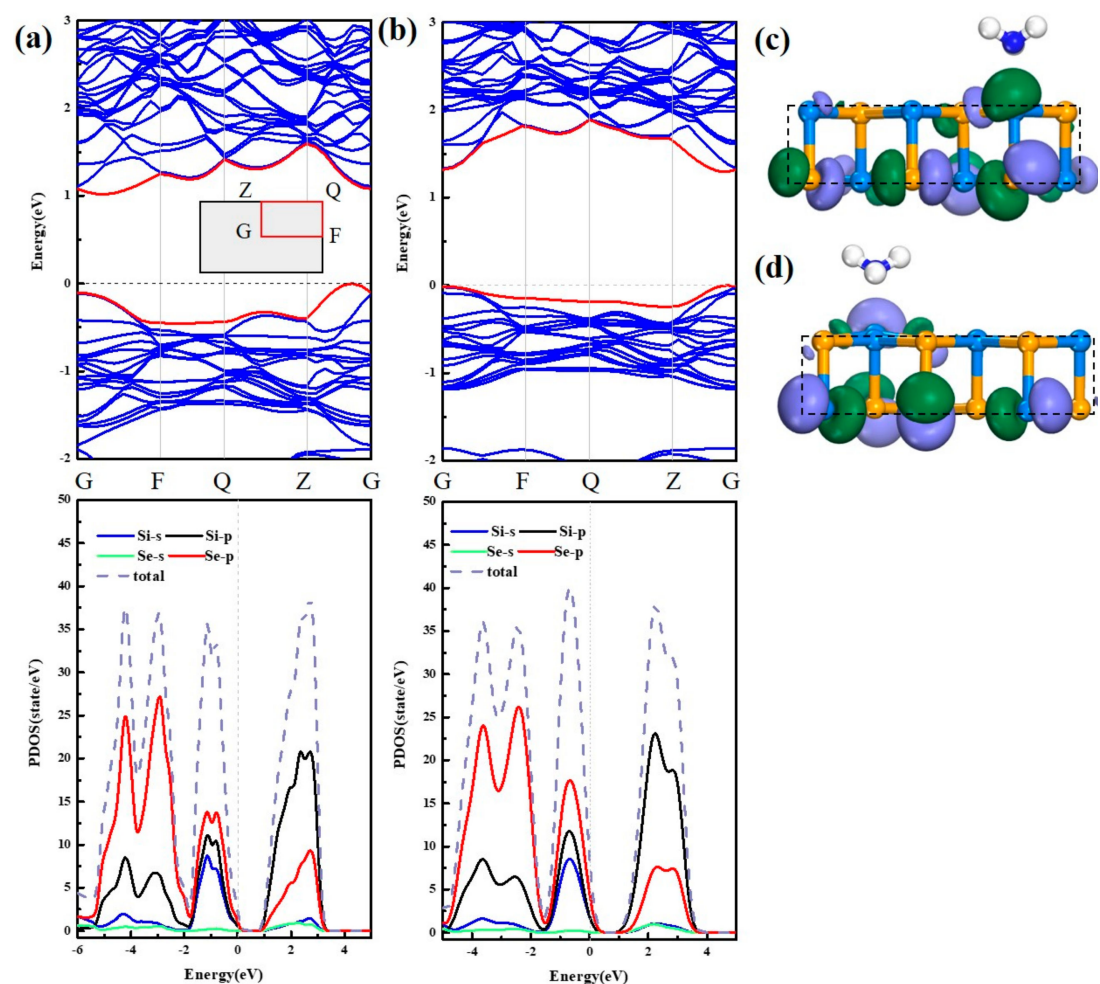

(d)
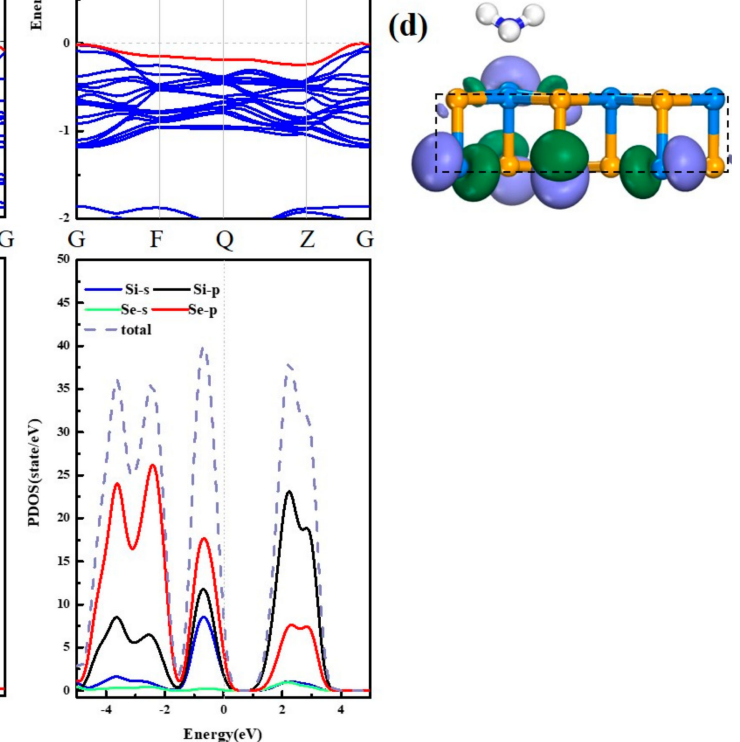

Figure 8. The band structure and PDOS of (a) $\mathrm{NH}_{3} /$ SiSe systems and (b) $8 \%$ tensile stress- $\mathrm{NH}_{3} / \mathrm{SiSe}$ systems, respectively. The inset of (a) is the Brillouin Zone path. The Fermi level (the dash line) is set to zero. (c) HUMO and (d) LUMO. 


\subsection{Adsorption Mechanism of $\mathrm{SO}_{2}$ Under Stress}

Since the adsorption of $\mathrm{SO}_{2}$ molecule by the SiSe monolayer is very close to the adsorption of $\mathrm{NH}_{3}$, it is hoped that the adsorption of $\mathrm{SO}_{2}$ molecule can be improved by stress, too. Similarly, stress is applied to the substrate from the $\mathrm{X}$-axis, the $\mathrm{Y}$-axis, and the $\mathrm{XY}$-biaxial direction, respectively, and then the $\mathrm{SO}_{2}$ molecule is adsorbed. The trend of adsorption strength is also the same as $\mathrm{NH}_{3}$ configuration: the increase of the tensile force causes the decrease of adsorption energy and the $\Delta Q$, while the increase of the pressure causes the increase of adsorption energy and the $\Delta \mathrm{Q}$. It has been previously analyzed that the adsorption of $\mathrm{SO}_{2}$ by the substrate with free-stress is chemisorption, and if the stretching method is employed to reduce the interaction between the substrate and the gas, it is possible to improve the adsorption of $\mathrm{SO}_{2}$ molecule for gas sensor. Furthermore, the $\mathrm{ELF}$ of $\mathrm{SO}_{2}$ with $8 \%$ stress added to the SiSe monolayer is explored. When the tensile stress of $\mathrm{X}$-axis is increasing, the adsorption energy reduces by $|0.073| \mathrm{eV}$ and the $\Delta \mathrm{Q}$ reduces by $0.32 \mathrm{e}$, showing a declining interaction between the substrate and molecule. However, the region of electron localization between the $\mathrm{Si}$ atom and the $\mathrm{S}$ atom still overlaps largely in Figure 9a, proving that chemisorption is still present. Although the adsorption energy and the transfer charge reduce more under the tensile stress of Y-axis or biaxial, such as the adsorption energy reaches $|-0.400| \mathrm{eV}$ and the $\Delta \mathrm{Q}$ reaches $|-0.208|$ e under biaxial stretching, but the ELF slice still demonstrates the hybridization between two parts. It is to say that the stress cannot adjust the adsorption of $\mathrm{SO}_{2}$ to an optimum state.

(a)

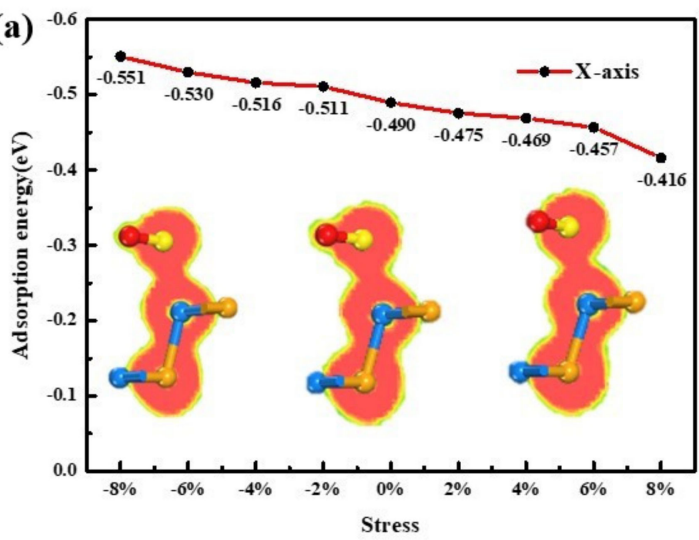

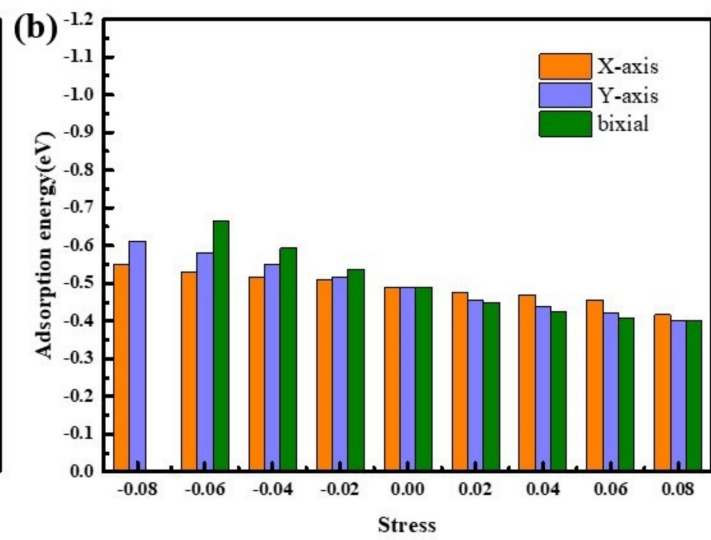

Figure 9. (a) The change curves of $\mathrm{E}_{a d}$ with tensile strain from $-8 \%$ to $8 \%$ in $\mathrm{SO}_{2} /$ strained-SiSe systems, ELF from left to right represents $-8 \%, 0 \%$, and $8 \%$ of stress. (b) The comparison of adsorption energy with the $\mathrm{X}$-axis, Y-axis, and biaxial under compressive strain from $-8 \%$ to $8 \%$ in $\mathrm{NH}_{3} /$ strained-SiSe systems.

On account of the small difference in adsorption of $\mathrm{NH}_{3}$ and $\mathrm{SO}_{2}$ based on SiSe substrate. It is necessary to discuss the co-adsorption mechanism of $\mathrm{SO}_{2}$ and $\mathrm{NH}_{3}$ gas on SiSe monolayer [50]. We consider three possible adsorption manners according to the actual situation: adsorption of $\mathrm{SO}_{2}$ and $\mathrm{NH}_{3}$ simultaneously (referred to as $\mathrm{SO}_{2}$ and $\mathrm{NH}_{3} / \mathrm{SiSe}$ ), adsorption of $\mathrm{SO}_{2}$ followed by adsorption of $\mathrm{NH}_{3}$ (referred as $\mathrm{SO}_{2}-\mathrm{NH}_{3} / \mathrm{SiSe}$ ) and adsorption of $\mathrm{NH}_{3}$ followed by adsorption of $\mathrm{SO}_{2}$ (referred as $\mathrm{NH}_{3}-\mathrm{SO}_{2} / \mathrm{SiSe}$ ). The results of the calculation are shown in the Table 5 and Table S2. Under these three cases, the substrate exhibits a different strength for gas adsorption. In the case of $\mathrm{SO}_{2}$ and $\mathrm{NH}_{3} / \mathrm{SiSe}$, the adsorption abilities to the $\mathrm{SO}_{2}$ molecule and the $\mathrm{NH}_{3}$ molecule both increase from the data analysis in the table. The $\Delta \mathrm{Q}$ of $\mathrm{NH}_{3}$ rises to $|0.241| \mathrm{e}$, which is $|0.063|$ e larger than initial. Meanwhile the $\Delta \mathrm{Q}$ of $\mathrm{SO}_{2}$ is 0.046 e larger than original. Both the distances between the molecules and substrate are shortened, with the $\mathrm{NH}_{3}$ reduced more seriously. It is easy to find that the same situation occurs in $\mathrm{NH}_{3}-\mathrm{SO}_{2} / \mathrm{SiSe}$. Hence, the co-adsorption of $\mathrm{NH}_{3}$ in the case of $\mathrm{SO}_{2}$ and $\mathrm{NH}_{3} / \mathrm{SiSe}$ and $\mathrm{NH}_{3}-\mathrm{SO}_{2} / \mathrm{SiSe}$ shows no sign of decline. Differently, when the SiSe monolayer first adsorbs the $\mathrm{SO}_{2}$ molecule and then adsorbs the $\mathrm{NH}_{3}$ molecule, the $\Delta \mathrm{Q}$ of $\mathrm{SO}_{2}$ decreases with the adsorption distance of $\mathrm{SO}_{2}$ increases comparing to the $\mathrm{SO}_{2} / \mathrm{SiSe}$ system, indicating that the interaction between the $\mathrm{SO}_{2}$ molecule and substrate is weakened. The adsorption of $\mathrm{NH}_{3}$ gas is improved comparing to $\mathrm{NH}_{3} / \mathrm{SiSe}$ 
system, which may due to the reason that electronegativity of the $\mathrm{N}$ atom is greater than $\mathrm{S}$ atom. The $\mathrm{N}$ and Si atom are more likely to get or lose electrons than the S and Si atom.

Table 5. Adsorption energy ( $\left.\mathrm{E}_{\mathrm{ad}}\right)$, Mulliken charge transfer $(\Delta \mathrm{Q})$, and closest distance $(\mathrm{d})$ of the $\mathrm{NH}_{3}$ molecule and the $\mathrm{SO}_{2}$ molecule, respectively in $\mathrm{SO}_{2}$ and $\mathrm{NH}_{3} / \mathrm{SiSe}, \mathrm{NH}_{3}-\mathrm{SO}_{2} / \mathrm{SiSe}$, and $\mathrm{SO}_{2}-\mathrm{NH}_{3} / \mathrm{SiSe}$ configurations.

\begin{tabular}{cccccc}
\hline Configuration & $E_{a d}(\mathrm{eV})$ & $\Delta Q_{(\mathrm{NH} 3)}(\mathrm{e})$ & $\Delta Q_{(\mathrm{SO} 2)}(\mathrm{e})$ & $d_{(\mathrm{NH})}(\AA)$ & $d_{(\mathrm{SO} 2)}(\AA)$ \\
\hline $\mathrm{SO}_{2}$ and $\mathrm{NH}_{3} / \mathrm{SiSe}$ & -1.161 & $0.241 \uparrow$ & $-0.276 \uparrow$ & $2.278 \downarrow$ & $2.646 \downarrow$ \\
$\mathrm{NH}_{3}-\mathrm{SO}_{2} / \mathrm{SiSe}$ & -0.752 & $0.243 \uparrow$ & $-0.278 \uparrow$ & $2.226 \downarrow$ & $2.639 \downarrow$ \\
$\mathrm{SO}_{2}-\mathrm{NH}_{3} / \mathrm{SiSe}$ & -0.465 & $0.196 \uparrow$ & $-0.220 \downarrow$ & $2.431 \downarrow$ & $2.760 \uparrow$ \\
\hline
\end{tabular}

\section{Conclusions}

In conclusion, ten different gase $\left(\mathrm{CO}, \mathrm{O}_{2}, \mathrm{CO}_{2}, \mathrm{CH}_{4}, \mathrm{H}_{2} \mathrm{~S}, \mathrm{H}_{2} \mathrm{O}, \mathrm{NH}_{3}, \mathrm{SO}_{2}, \mathrm{NO}, \mathrm{NO}_{2}\right)$ of adsorption on SiSe monolayer have been studied. From the perspective of adsorption energy, DOS, PDOS, CCD, and ELF, it is found that $\mathrm{NH}_{3}$ molecule is physical adsorption with moderate adsorption energy of $0.414 \mathrm{eV}$, which is the most suitable as gas sensor material. On the contrary, the adsorption of $\mathrm{SO}_{2}$ belongs to chemical adsorption with large adsorption energy $(0.490 \mathrm{eV})$, both $\mathrm{NO}$ and $\mathrm{NO}_{2}$ are equipped with the largest adsorption energy $(0.734 \mathrm{eV}, 0.735 \mathrm{eV})$, which can be applied in one-time gas sensor. Further, stress is applied to adjust the adsorption performance of SiSe monolayer to adsorb $\mathrm{NH}_{3}$ and $\mathrm{SO}_{2}$ molecules. The results reveal that compressive strain causes the sensitive material sensor to develop toward larger adsorption energy, and the tensile strain changes inversely. Thus, when the stress increases to $-2 \%$ in the $\mathrm{X}$-axis, the adsorption of $\mathrm{NH}_{3}$ is enhanced with the adsorption energy increases to $|-0.426| \mathrm{eV}$, which maintains the physical adsorption of $\mathrm{NH}_{3}$. While for $\mathrm{SO}_{2}$ molecule, the strength of chemical adsorption based on SiSe monolayer is increased under compressive stress. In addition, due to the small difference of $\mathrm{SO}_{2}$ and $\mathrm{NH}_{3}$ molecules, the co-adsorption of these two gases on substrate shows that the adsorption of $\mathrm{NH}_{3}$ is promoted at three different situations, even the adsorption of $\mathrm{SO}_{2}$ will be suppressed when the $\mathrm{SO}_{2}$ is first adsorbed on SiSe monolayer. Therefore, it is expected that the SiSe monolayer is a potential candidate to be applied in $\mathrm{NH}_{3}$ gas sensors.

Supplementary Materials: The following are available online at http://www.mdpi.com/1424-8220/20/4/977/s1, Figure S1-S4, Table S1-S2.

Author Contributions: Conceptualization, Q.Z. and L.L.; writing一original draft preparation, Q.Z. and Q.L.; writing-review and editing, Z.W. review, editing, and theoretical suggestion, C.G.; supervision, Y.L.; project administration and funding acquisition, H.Y. All authors have read and agree to the published version of the manuscript.

Funding: This work was supported by the National Key R\&D Program of China (No. 2018YFE0204600), key-Area Research and Development Program of GuangDong Province (No. 2019B010131001), National Natural Science Foundation of China under Grant No. 51706029.

Conflicts of Interest: The authors declare no conflict of interest.

\section{References}

1. Zhang, J.; Qin, Z.; Zeng, D.; Xie, C. Metal-oxide-semiconductor based gas sensors: Screening, preparation, and integration. Phys. Chem. Chem. Phys. 2017, 19, 6313-6329. [CrossRef] [PubMed]

2. Joshi, N.; Hayasaka, T.; Liu, Y.; Liu, H.; Oliveira, O.N.; Lin, L. A review on chemiresistive room temperature gas sensors based on metal oxide nanostructures, graphene and 2D transition metal dichalcogenides. Microchim. Acta 2018, 185, 213. [CrossRef] [PubMed]

3. Wella, S.A.; Aditya, I.D.; Wungu, T.D.K. Density Functional Theory (DFT) Study: Electronic Properties of Silicene under Uniaxial Strain as H2S Gas Sensor. Key Eng. Mater. 2016, 675-676, 15-18.

4. Ma, S.; Yuan, D.; Wang, Y.; Jiao, Z. Monolayer GeS as a potential candidate for $\mathrm{NO}_{2}$ gas sensor and capturer. J. Mater. Chem. C 2018, 6, 8082-8091. [CrossRef]

5. Ahn, M.W.; Park, K.S.; Heo, J.H.; Park, J.G.; Kim, D.W.; Choi, K.J.; Lee, J.H.; Hong, S.H. Gas Sensing Properties of Defect-Controlled ZnO-Nanowire Gas Sensor. Appl. Phys. Lett. 2008, 93, 1502. [CrossRef] 
6. Ren, J.; Kong, W.; Ni, J. The Potential Application of BAs for a Gas Sensor for Detecting $\mathrm{SO}_{2}$ Gas Molecule: A DFT Study. Nanoscale Res. Lett. 2019, 14, 133. [CrossRef]

7. Guo, S.; Lu, Y.; Liu, X.; Zhou, W.; Song, X.; Zhang, S. First-principles study of $\mathrm{SO}_{2}$ sensors based on phosphorene and its isoelectronic counterparts: GeS, GeSe, SnS, SnSe. Chem. Phys. Lett. 2017, 686, 83-87. [CrossRef]

8. Mirzaei, A.; Leonardi, S.G.; Neri, G. Detection of hazardous volatile organic compounds (VOCs) by metal oxide nanostructures-based gas sensors: A review. Ceram. Int. 2016, 42, 15119-15141. [CrossRef]

9. Huiru, Y.; Zeping, W.; Huaiyu, Y.; Kai, Z.; Xianping, C.; Guoqi, Z. Promoting sensitivity and selectivity of HCHO sensor based on strained $\mathrm{InP}_{3}$ monolayer: A DFT study. Appl. Surf. Sci. 2018, 459, 554-561.

10. Bo, X.; Li, Y.C.; Yu, X.F.; Cheng, J.B. MXenes: Reusable materials for $\mathrm{NH}_{3}$ sensor or capturer by controlling the charge injection. Sens. Actuators B Chem. 2016, 235, 103-109.

11. Yamazoe, N. Toward innovations of gas sensor technology. Sens. Actuators B Chem. 2005, 108, 2-14. [CrossRef]

12. Choi, J.K.; Hwang, I.S.; Kim, S.J.; Park, J.S.; Park, S.S.; Jeong, U.; Yun, C.K.; Lee, J.H. Design of selective gas sensors using electrospun Pd-doped SnO2 hollow nanofibers. Sens. Actuators B Chem. 2010, 150, 191-199. [CrossRef]

13. Yang, S.; Jiang, C.; Wei, S. Gas sensing in 2D materials. Appl. Phys. Rev. 2017, 4, 021304. [CrossRef]

14. Kannan, P.K.; Late, D.J.; Morgan, H.; Rout, C.S. Recent developments in 2D layered inorganic nanomaterials for sensing. Nanoscale 2015, 7, 13293-13312. [CrossRef] [PubMed]

15. Peyghan, A.A.; Rastegar, S.F.; Hadipour, N.L. DFT study of $\mathrm{NH}_{3}$ adsorption on pristine, Ni- and Si-doped graphynes. Phys. Lett. A 2014, 378, 2184-2190. [CrossRef]

16. Liang, X.Y.; Ding, N.; Ng, S.P.; Wu, C.M.L. Adsorption of gas molecules on Ga-doped graphene and effect of applied electric field: A DFT study. Appl. Surf. Sci. 2017, 411,11-17. [CrossRef]

17. Guo, H.; Zhang, W.; Ning, L.; Zhuo, Z.; Xiao, C.Z.; Wu, X.; Yang, J. CO 2 Capture on h-BN Sheet with High Selectivity Controlled by External Electric Field. J. Phys. Chem. C 2015, 119, 6912-6917. [CrossRef]

18. Zhu, J.; Ha, E.; Zhao, G.; Zhou, Y. Recent advance in MXenes: A promising 2D material for catalysis, sensor and chemical adsorption. Coord. Chem. Rev. 2017, 352, 306-327. [CrossRef]

19. Yu, X.F.; Li, Y.C.; Cheng, J.B.; Liu, Z.B.; Li, Q.Z.; Li, W.Z.; Yang, X.; Xiao, B. Monolayer Ti ${ }_{2} \mathrm{CO}_{2}$ : A Promising Candidate for $\mathrm{NH}_{3}$ Sensor or Capturer with High Sensitivity and Selectivity. ACS Appl. Mater. Interfaces 2015, 7, 13707-13713. [CrossRef]

20. Ma, S.H.; Yuan, D.; Jiao, Z.Y.; Wang, T.X.; Dai, X. Monolayer $\mathrm{Sc}_{2} \mathrm{CO}_{2}$ : A Promising Candidate as $\mathrm{SO}_{2} \mathrm{Gas}$ Sensor or Capturer. J. Phys. Chem. C 2017, 121, 24077-24084. [CrossRef]

21. Park, M.; Park, Y.J.; Chen, X.; Park, Y.K.; Kim, M.S.; Ahn, J.H. MoS2-Based Tactile Sensor for Electronic Skin Applications. Adv. Mater. 2016, 28, 2556-2562. [CrossRef] [PubMed]

22. Wasey, A.H.M.A.; Chakrabarty, S.; Das, G.P. Quantum size effects in layered $\mathrm{VX}_{2}(\mathrm{X}=\mathrm{S}, \mathrm{Se}, \mathrm{Te})$ materials: Manifestation of metal to semimetal or semiconductor transition. J. Appl. Phys. 2015, 117, 064313. [CrossRef]

23. Docherty, C.J.; Lin, C.T.; Joyce, H.J.; Nicholas, R.J.; Herz, L.M.; Li, L.J.; Johnston, M.B. Extreme sensitivity of graphene photoconductivity to environmental gases. Nat. Commun. 2012, 3, 1228. [CrossRef] [PubMed]

24. Schedin, F.; Geim, A.K.; Morozov, S.V.; Hill, E.W.; Blake, P.; Katsnelson, M.I.; Novoselov, K.S. Detection of individual gas molecules adsorbed on graphene. Nat. Mater. 2007, 6, 652-655. [CrossRef] [PubMed]

25. Yuan, W.; Shi, G. Graphene-based gas sensors. J. Mater. Chem. A 2013, 1, 10078-10091. [CrossRef]

26. Cui, S.; Pu, H.; Wells, S.A.; Wen, Z.; Mao, S.; Chang, J.; Hersam, M.C.; Chen, J. Ultrahigh sensitivity and layer-dependent sensing performance of phosphorene-based gas sensors. Nat. Commun. 2015, 6, 8632. [CrossRef]

27. Kou, L.; Frauenheim, T.; Chen, C. Phosphorene as a Superior Gas Sensor: Selective Adsorption and Distinct I-V Response. J. Phys. Chem. Lett. 2014, 5, 2675-2681. [CrossRef]

28. Chen, P.F.; Li, N.; Chen, X.Z.; Ong, W.J.; Zhao, X.J. The rising star of 2D black phosphorus beyond graphene: Synthesis, properties and electronic applications. 2D Mater. 2018, 5, 21. [CrossRef]

29. Abbas, A.N.; Liu, B.; Chen, L.; Ma, Y.; Cong, S.; Aroonyadet, N.; KoPf, M.; Nilges, T.; Zhou, C. Black phosphorus gas sensors. Acs Nano 2015, 9, 5618-5624. [CrossRef]

30. Wei, Q.; Peng, X. Superior mechanical flexibility of phosphorene and few-layer black phosphorus. Appl. Phys. Lett. 2014, 104, 372-398. [CrossRef]

31. Yang, G.; Ma, T.; Peng, X. Superior mechanical flexibility and strained-engineered direct-indirect band gap transition of green phosphorene. Appl. Phys. Lett. 2018, 112, 241904. [CrossRef] 
32. Gomes, L.C.; Carvalho, A. Phosphorene analogues: Isoelectronic two-dimensional group-IV monochalcogenides with orthorhombic structure. Phys. Rev. B 2015, 92, 085406. [CrossRef]

33. Li, Z.Y.; Liu, M.Y.; Huang, Y.; Chen, Q.Y.; Cao, C.; He, Y. Tuning the electronic properties of bilayer group-IV monochalcogenides by stacking order, strain and an electric field: A computational study. Phys. Chem. Chem. Phys. 2017, 20, 214-220. [CrossRef] [PubMed]

34. Sa, B.; Sun, Z.; Wu, B. The development of two dimensional group IV chalcogenides, blocks for van der Waals heterostructures. Nanoscale 2016, 8, 1169-1178. [CrossRef]

35. Yang, J.H.; Yuan, Q.; Deng, H.; Wei, S.H.; Yakobson, B.I. Earth-Abundant and Non-Toxic SiX (X = S, Se) Monolayers as Highly Efficient Thermoelectric Materials. J. Phys. Chem. C 2017, 121, 123-128. [CrossRef]

36. Jiang, H.R.; Zhao, T.S.; Ren, Y.X.; Zhang, R.H.; Wu, M.C. Ab initio prediction and characterization of phosphorene-like SiS and SiSe as anode materials for sodium-ion batteries. Sci. Bull. 2017, 62, 572-578. [CrossRef]

37. Karmakar, S.; Chowdhury, C.; Datta, A. Two-Dimensional Group IV Monochalcogenides: Anode Materials for Li-Ion Batteries. J. Phys. Chem. C 2016, 120, 14522-14530. [CrossRef]

38. Mao, Y.L.; Ben, J.; Yuan, J.M.; Zhong, J.X. Tuning the electronic property of two dimensional SiSe monolayer by in-plane strain. Chem. Phys. Lett. 2018, 705, 12-18. [CrossRef]

39. Perdew, J.P.; Burke, K.; Wang, Y. Generalized gradient approximation for the exchange-correlation hole of a many-electron system. Phys. Rev. B 1996, 54, 16533-16539. [CrossRef]

40. Ernzerhof, M.; Scuseria, G.E. Assessment of the Perdew-Burke-Ernzerhof exchange-correlation functional. J. Chem. Phys. 1999, 110, 5029-5036. [CrossRef]

41. Perdew, J.P.; Burke, K.; Ernzerhof, M. Generalized Gradient Approximation Made Simple. Phys. Rev. Lett. 1996, 77, 3865-3868. [CrossRef] [PubMed]

42. Appalakondaiah, S.; Vaitheeswaran, G.; Lebègue, S.; Christensen, N.E.; Svane, A. Effect of van der Waals interactions on the structural and elastic properties of black phosphorus. Phys. Rev. B 2012, 86, 035105. [CrossRef]

43. Liu, L.; Yang, Q.; Ye, H.Y.; Chen, X.P.; Zhang, G.Q. Adsorption of gases on monolayer GeSe: A first principle study. In Proceedings of the 18th International Conference on Thermal, Mechanical and Multi-Physics Simulation and Experiments in Microelectronics and Microsystems (EuroSimE), Dresden, Germany, 3-5 April 2017.

44. Ye, H.; Liu, L.; Xu, Y.; Wang, L.; Chen, X.; Zhang, K.; Liu, Y.F.; Koh, S.W.; Zhang, G. SnSe monolayer: A promising candidate of SO2 sensor with high adsorption quantity. Appl. Surf. Sci. 2019, 484, 33-38. [CrossRef]

45. Rodin, A.S.; Carvalho, A.; Castro Neto, A.H. Strain-Induced Gap Modification in Black Phosphorus. Phys. Rev. Lett. 2014, 112, 176801. [CrossRef] [PubMed]

46. Nguyen, C.V.; Hieu, N.N. Effect of biaxial strain and external electric field on electronic properties of MoS 2 monolayer: A first-principle study. Chem. Phys. 2016, 468, 9-14. [CrossRef]

47. Naumis, G.G.; Barraza-Lopez, S.; Oliva-Leyva, M.; Terrones, H. A review of the electronic and optical properties of strained graphene and other similar 2D materials. Rep. Prog. Phys. 2017, 80, 096501. [CrossRef]

48. Zhang, L.; Tang, Z.K.; Lau, L.; Yin, W.J.; Liu, L.M. Tuning band gaps and optical absorption of BiOCl through doping and strain: Insight form DFT calculations. Phys. Chem. Chem. Phys. 2017, 19, 20968-20973. [CrossRef]

49. Yu, Z.; Bo, S.; Li, L.; Lei, J. Coupling effects of strain on structural transformation and bandgap engineering in SnS monolayer. RSC Adv. 2017, 7, 30327-30333.

50. Gao, C.; Zhang, Y.; Yang, H.; Liu, Y.; Liu, Y.; Du, J.; Ye, H.; Zhang, G. A DFT study of In doped Tl2O: A superior NO2 gas sensor with selective adsorption and distinct optical response. Appl. Surf. Sci. 2019, 494, 162-169. [CrossRef]

(C) 2020 by the authors. Licensee MDPI, Basel, Switzerland. This article is an open access article distributed under the terms and conditions of the Creative Commons Attribution (CC BY) license (http://creativecommons.org/licenses/by/4.0/). 